\title{
Типохимизм берилла Шерловой Горы (Юго-Восточное Забайкалье)
}

\author{
Юргенсон Г.А. ${ }^{1}$, Афанасьева А.С. ${ }^{2}$, Борзенко А.А. ${ }^{1}$, Кононов О.В. ${ }^{2}$ \\ ${ }^{1}$ Институт природных ресурсов, экологии и криологии СО РAH, Чита, yurgga@mail.ru \\ ${ }^{2}$ Московский государственныий университет им. М.В. Ломоносова, Москва, \\ asafanasyeva@rusgeology.ru
}

Аннотация. Приведены новые данные о химическом составе берилла месторождения висмута, олова, вольфрама и ювелирных камней Шерловая гора. Среди кристаллов берилла развиты аквамарин, зеленый берилл и гелиодор. Обобщено более 200 химических и микрозондовых анализов и определено, что берилл слабощелочной: содержания $\mathrm{Na}$ 0.01-0.09 формульных коэффициентов, a Cs - 0.0005-0.0041, и по их содержанию бериллы не различаются. В аквамарине преобладает двухвалентное Fe, гелиодоре трехвалентное, в зеленом их содержание примерно равное. Это подтверждено данными оптической спектроскопии: максимум поглощения в области 700 и $800 \mathrm{~nm}^{-1}$ типично для закисного Fе аквамарина, минимум - для гелиодора, а окисного в области $360 \mathrm{~nm}^{-1}$ для гелиодора. Установлена корреляция между цветом и интенсивностью ЭПР-сигнала $\mathrm{Fe}^{3+}$. Типохимическим признаком зеленого берилла Шерловой Горы является максимально высокое содержание V и примерно равные соотношения двух- и трехвалентного Fе. Минимально содержание V в кристаллах голубого берилла.

Ключевые слова: берилл, аквамарин, зеленый берилл, гелиодор, окисно-закисные формы железа, ванадий, скандий, Шерловая Гора, Забайкалье.

\section{Typochemism of beryl of Sherlovaya Mountain (Southeastern Transbaikalia)}

Yurgenson G.A. ${ }^{1}$, Afanasyeva A.S. ${ }^{2}$, Borzenko A.A. ${ }^{1}$, Kononov O.V. ${ }^{2}$

${ }^{1}$ Institute of Natural Resources, Ecology and CryologySB RAS, Chita, yurgga@mail.ru

${ }^{2}$ Moscow State University.MV Lomonosov, Moscow, asafanasyeva@rusgeology.

Abstract. New data on the chemical composition of the beryl deposits of bismuth, tin, tungsten and jewelry stones Sherlovaya Mountain are given. Among beryl crystals, aquamarine, green beryl and heliodor are developed. More than 200 chemical and microprobe analyzes have been compiled and it is determined that the beryl is weakly alkaline: the content of $\mathrm{Na}$ 0.003-0.012 formula coefficients, and $\mathrm{Cs}-0.0005-0.0041$ and the content of beryl does not differ. In aquamarine, bivalent Fe prevails, trivalent in heliodor, in green their content is approximately equal. As confirmed by optical spectroscopy data, the absorption maximum in the region of 700 and $800 \mathrm{~nm}-1$ is typical of fermented Fe aquamarine, the minimum is for the heliodor, and the oxide one in the region of $360 \mathrm{~nm}-1 \mathrm{for}$ the heliodor. The correlation between the color and intensity of the EPR signal $\mathrm{Fe}^{3+}$ has been established. The typochemical characteristic of green beryl of the Sherlovaya Gora is the highest V content and approximately equal ratios of divalent and trivalent Fe. The content of $\mathrm{V}$ in crystals of blue beryl is minimal.

Keywords: beryl, aquamarine, green beryl, heliodor, ferric oxide forms, vanadium, scandium, Sherlovaya Gora, Transbaikalia.

\section{Введение}

Месторождение находится в Моноголо-Охотской минерагенической зоне в Юго-Восточном Забайкалье России (рис. 1). Оно локализовано в Шерловогрском гранитном массиве, являющемся частью вулкано-плутонической системы, приуроченной к сочленению Агинского жесткого массива, сложенного метаморфизованными терригенными горными породами палеозойского возраста и Харанорской рифтовой впадины, выполненной вулканогенно-осадочными отложениями мезозойского возраста.

Шерловогрский гранитный шток кукульбейского интрузивного комплекса, радиологический возраст которого, определенный калий-аргоновым методом, составляет 154-147 млн. лет, представляет собою восточный фрагмент Адун-Челон- Шерловогорского интрузивного тела (Гайворонский, 1995). Он входит в состав одноименной рудно-магматической системы и представлен на рис. 2. 


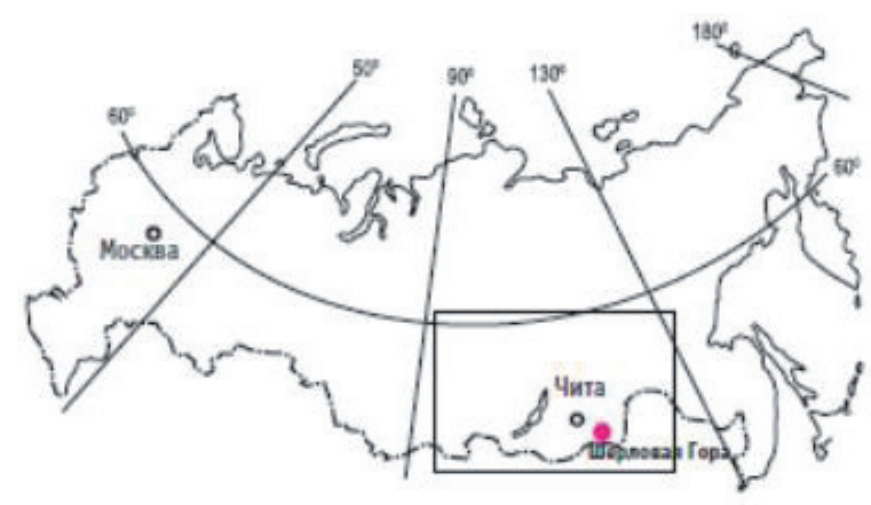

Рис. 1. Местонахождение месторождения Шерловая Гора.

Fig. 1. Location of the Sherlovaya Gora deposit.

В статье рассматриваются результаты изучения берилла месторождения самоцветов Шерловая Гора, локализованного в грейзенах и грейзененизированных гранитах Шерловогоского массива, хотя, строго говоря, берилл в тех или иных количествах развит и на Аплитовом и Кварц-турмалиновом отрогах, а также в жильном комплексе олово-полиметаллического месторождения Сопка Большая. Но его ювелирные разности известны только в кварцево-жильном комплексе Шерловой Горы. Основные участки добычи ювелирного берилла, исторически определившиеся за 300 лет разработки месторождения, показаны на рисунке 2 .

Месторождение открыто в 1723 году и, несмотря на то, что приближается 300-летие его изучения и отработки, оно продолжает оставаться почти единственным в России источником благород-

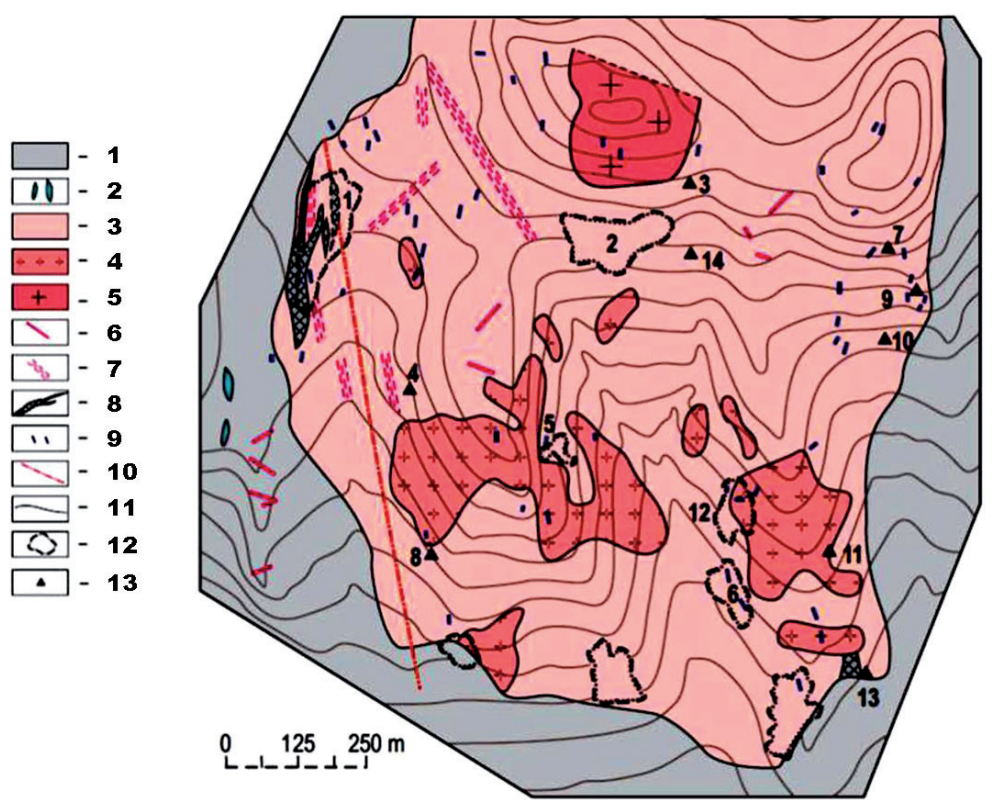

Рис. 2. Геологическая карта Шерловогорского месторождения аквамарина с указанием основных мест добычи самоцветов. Составлена с использованием геологической основы (В.В. Аристова и др., 1961).

1 - роговики, 2 - габбро, диориты, 3 - граниты порфировидные, 4 - граниты крупнозернистые, 5 - гранитпорфиры, 6 - аплиты, 7 - зоны трещиноватости; 8 - грейзеновые тела, 9 - внемасштабные зоны грейзенизации, 10 - зоны дробления, 11 - геологические границы, 12 - старые выработки и отвалы и их номера на карте, 13 - внемсаштабные выработки и их номера. Горные выработки на карте: 1 - Поднебесных, 2 - Новиковская, 3 - Белотопазовая, 4 - Мелехинская-1, 5 - Мелехинская-2, 6 - Гелиодоровая, 7 - Лизкина Яма, 8 - Мелехинская, 9 - Кондратьевская, 10 - Золотой Мыс, 11 - Лукаво-Золотая, 12 - Миллионная, 13 - Золотой Отрог.

Fig. 2. Geological map of the Sherlovogorsk aquamarine deposit indicating the main places of gem mining. Compiled using the geological basis (V.V. Aristov et al., 1961).

1 - hornfels, 2 - gabbros, diorites, 3 - porphyry granites, 4 - coarse granites, 5 - granite porphyry, 6 -aplites, 7 - fracture zones, 8 - greisen bodies, 9 - off-scale greisenization zones, 10 - crushing zones , 11 - geological boundaries, 12 - old workings and dumps and their numbers on the map, 13 - out-of-scale workings and their numbers. Mine workings on the map: 1 - Podnebesnykch, 2 - Novikovskaya, 3 - Belotopazovaya, 4 - Melekhinskaya-1, 5 -Melekhinskaya-2, 6 - Heliodorovaya, 7 - Lizkina Yama, 8 - Melekhinskaya, 9 - Kondratievskaya, 10 - Golden Cape, 11 - LukavoZolotaya, 12 - Millionnaya, 13 - Zolotoy Otrog. 
ных разновидностей берилла ювелирного качества, неповторимых по разнообразию и насыщенности цвета. В 1787 г. месторождение стало собственностью императрицы Екатерины II, которая организовала систематическую многолетнюю добычу. По современным оценкам, за почти 300-летний период добыто более 5 т кондиционного кристаллосырья (Юргенсон, 2001).

Целью работы является изучение вариаций химического состава ювелирных разновидностей берилла и выявление их типохимических признаков.

\section{Материал и методы исследования}

Для изучения использована коллекция, включающая более 300 разноцветных кристаллов берилла и их фрагментов, собранных за многие годы на разных участках месторождения, обозначенных на рис. 2. Коллекция состояла из кристаллов аквамарина, зеленого берилла и гелиодора, отличающихся оттенками и насыщенностью голубой, зеленой и желто-оранжевой окраски. Изменчивость химического состава изучена с использовнием 152 оригинальных микрозондовых (МГУ) и химических анализов методом ICP MS (АО Восток-Лимитед, г. Чита). Выполнены также исследования спектроскопических свойств методами: оптической (45 спектров), инфракрасной (30 спектров) и ЭПР-спектроскопии (30 спектров).

\section{Результаты и их обсуждение}

Результате более 200 химических и микрозондовых анализов показали, что все цветные разновидности берилла относятся к слабощелочным (рис. 3). Содержания Na находится в пределах

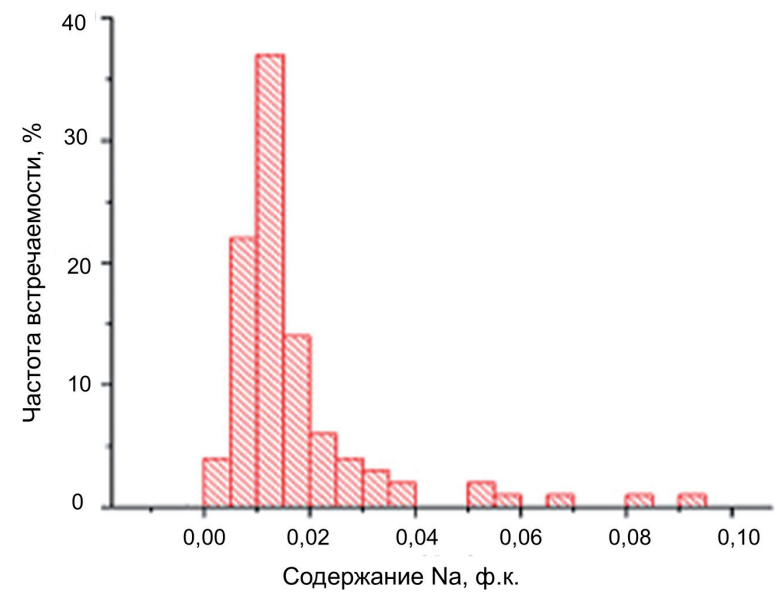

Рис. 3. Содержания Na во всех кристаллах берилла.

Fig. 3. Na content in all beryl crystals.

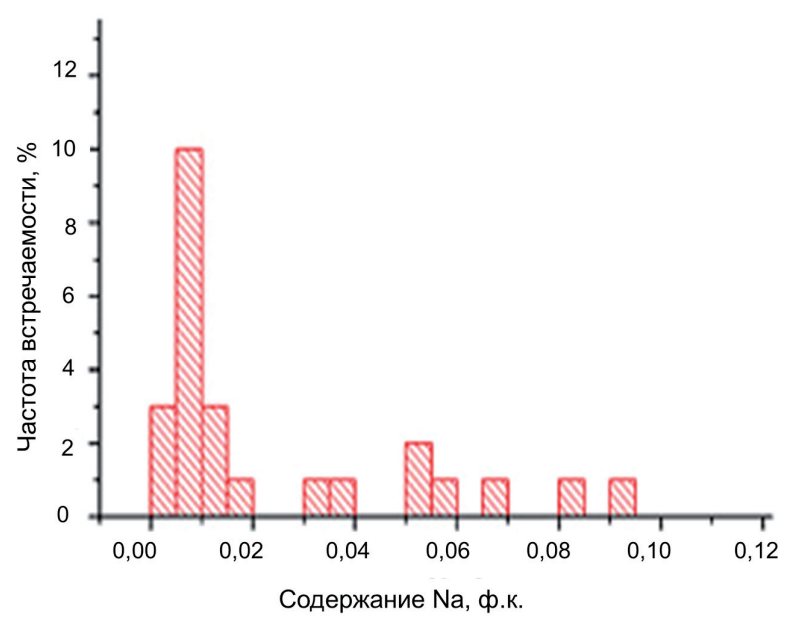

Рис. 5. Содержания Na в гелиодоре.

Fig. 5. Na content in heliodore.

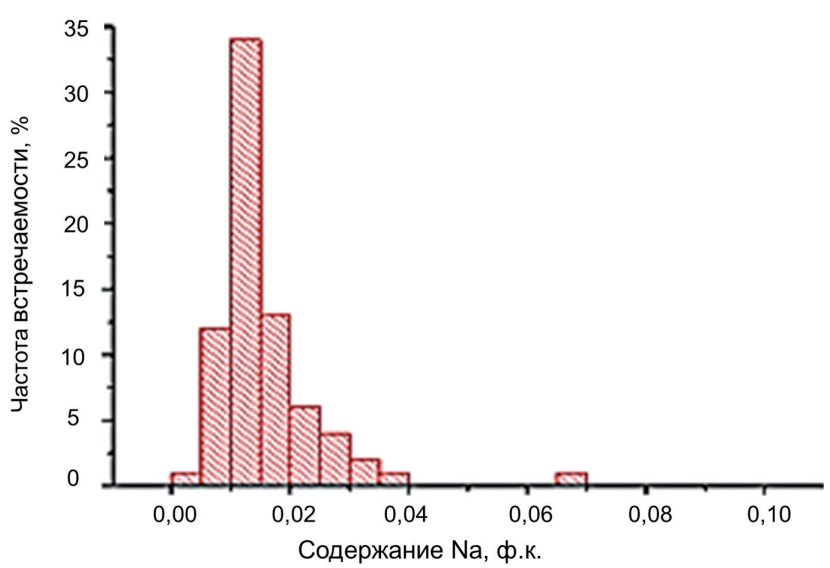

Рис. 4. Содержания $\mathrm{Na}$ в аквамарине.

Fig. 4. Na content in aquamarine.

0.01-0.09 ф.к. При этом для аквамарина максимальная частота встречаемости (34\%) типична для содержаний 0.01-0.02 ф.к.

Для гелиодора при максимальном содержании натрия 0.095 ф.к. типичен широкий диапазон содержаний (0.005-0.095 ф.к.), тем не менее, наибольшая частота, равная $10 \%$ присуща значениям 0.01 ф.к. (рис. 5). Содержания Cs 0.0005-0.0041 ф.к., и по ним изученные кристаллы берилла различаются несущественно.

Как известно, Fе является важнейшим хромофором берилла. Из таблицы, где представлены данные химических анализов 42 кристаллов берилла, по содержанию общего железа аквамарин, зеленый берилл и зелено-желтые раз- 
ности гелиодора различаются по-разному, подчеркивая природное разделение кристаллов берилла по цветам на три группы. В ряду бесцветные и голубые среднее содержания железа максимально (0.45-1.02 \%), увеличиваясь с возрастанием интенсивности голубой окраски. Среди зеленых наиболее высоким содержанием общего железа отличаются голубовато-зеленые (почти аквамарины). При этом оно уменьшается у собственно зеленых бериллов (0.44). В группе кристаллов берилла, которые можно отнести к гелиодорам с различным зеленым оттенком, содержания общего железа возрастают по мере увеличения доли желтой окраски от 0.44 \% у зеленых до $0.89 \%$ у оливковозеленых гелиодоров.

Таблица. Статистические характеристики содержаний ванадия, железа и алюминия в бериллах различной окраски.

Table. Statistical features of contents of vanadium, iron and aluminum in beryls of various colors.

\begin{tabular}{|c|c|c|c|c|c|c|}
\hline \multirow{3}{*}{ Цвет } & \multicolumn{6}{|c|}{$\begin{array}{c}\text { Элемент и статистические характеристики его содер- } \\
\text { жания, мас.\% }\end{array}$} \\
\hline & \multicolumn{3}{|c|}{ Ванадий } & \multicolumn{3}{|c|}{ Железо } \\
\hline & $\mathrm{n}$ & $\mathrm{x}$ & $\sigma$ & $\mathrm{n}$ & $\mathrm{x}$ & $\sigma$ \\
\hline $\begin{array}{l}\text { Бледно-голубой, } \\
\text { почти бесцветный }\end{array}$ & 4 & 0.0005 & 0.0002 & 4 & 0.45 & 0.0681 . \\
\hline Бледно-голубой & 3 & 0.0005 & 0 & 3 & 0.65 & 0.1709 \\
\hline Ярко-голубой & 3 & 0.0005 & 0 & 2 & 1.02 & 0.1487 \\
\hline Зеленовато-голубой & 10 & 0.0008 & 0 & 9 & 0.59 & 0.1536 \\
\hline Светло-зеленый & 3 & 0.0008 & 0.0003 & 3 & 0.49 & 0.0387 \\
\hline Зеленый & 8 & 0.0016 & 0.0012 & 8 & 0.44 & 0.0772 \\
\hline Желтовато-зеленый гелиодор & 4 & 0.0012 & 0.0005 & 10 & 0.57 & 0.0871 \\
\hline Зеленовато-желтый гелиодор & 5 & 0.0006 & 0.00025 & 4 & 0.62 & 0.0608 \\
\hline Оливково-зеленый гелиодор & 2 & 0.0005 & 0 & 2 & 0.89 & 0.1414 \\
\hline
\end{tabular}

Весьма важным типохимическим признаком берилла различной окраски является соотношение содержаний окисного и закисного $\mathrm{Fe}$ в берилле. В аквамарине преобладает двухвалентное $\mathrm{Fe}$, гелиодоре - трехвалентное, а в зеленом их содержание примерно равное. Это подтверждено данными оптической спектроскопии: максимум поглощения в области 700 и $800 \mathrm{~nm}^{-1}$ типично для закис-

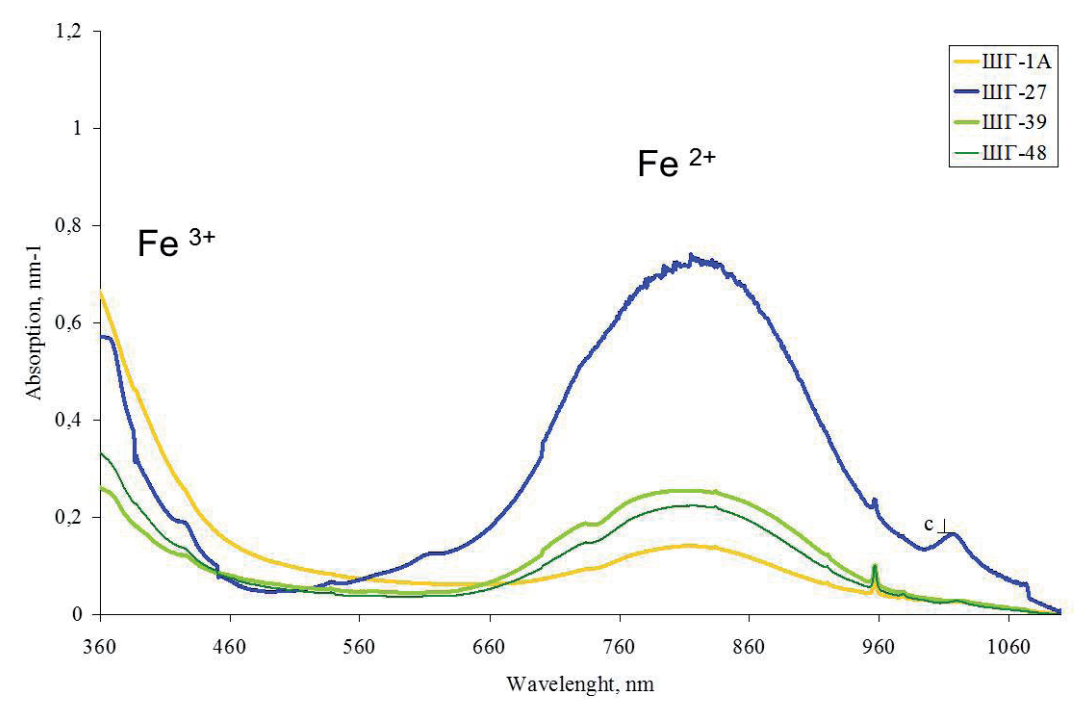

Рис. 6. Оптические спектры двух- и трехвалентного железа в кристаллах различной окраски: ШГ-1А гелиодор, ШГ-27 - аквамарин, ШГ-38 и ШГ-48, соответственно, зеленый и желто-зеленый разности.

Fig. 6. Optical spectra of bivalent and trivalent iron in crystals of various colors: ShG-1A heliodor, ShG-27 - aquamarine, ShG-38 and ShG-48, respectively, are green and yellow-green varieties. 


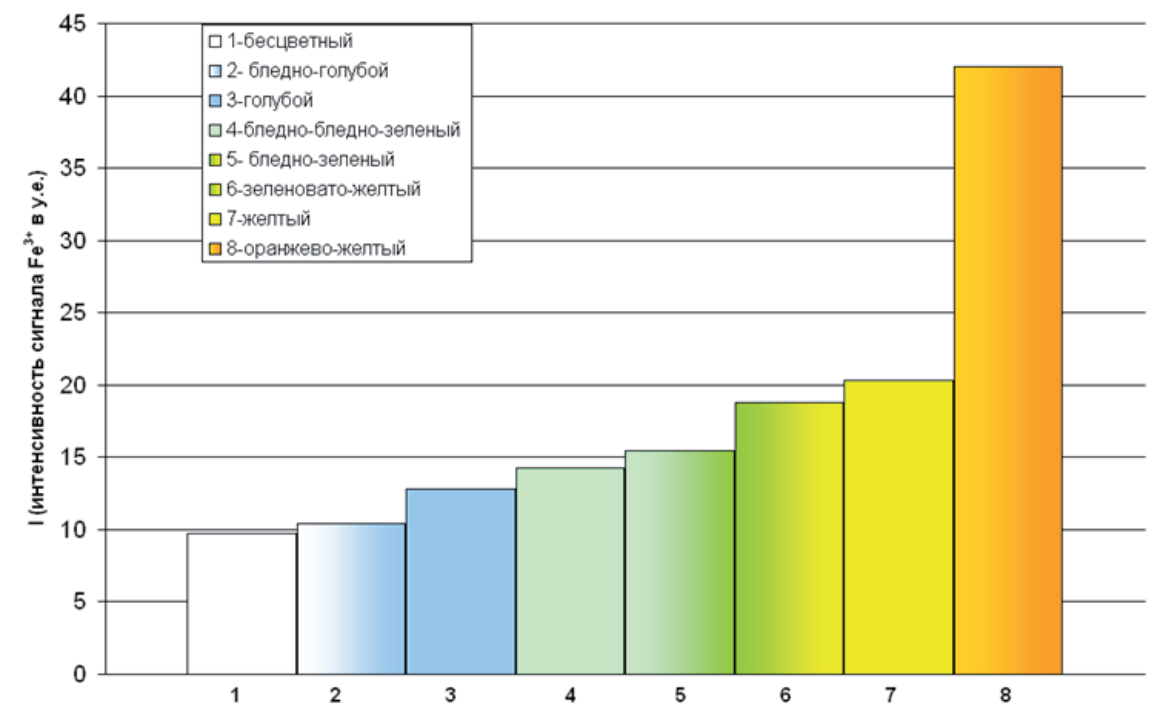

Рис. 7. Связь окраски берилла и содержания $\mathrm{Fe}^{3+}$ в нём.

Fig. 7. Relationship of beryl coloration and $\mathrm{Fe} 3^{+}$content in it.

ного Fe аквамарина, минимум - для гелиодора, а окисного в области $360 \mathrm{~nm}^{-1}$ для гелиодора (рис. 6). Установлена корреляция между цветом и интенсивностью ЭПР-сигнала $\mathrm{Fe}^{3+}$ (рис. 7).

По данным ЭПР спектроскопии (рис. 7) получена четкая картина возрастания доли трехвалентного железа в ряду: бесцветный- бледно-голубой-голубой- зеленый - желтый и желто-оранжевый.

В ряду бесцветные и голубые среднее содержания железа минимально $(0.0005 \%)$. Среди зеленых наиболее высоким средним содержанием общего железа отличаются ярко-зеленые кристаллы $(0.0016$ \%). Как типохимический признак можно рассматривать вариации содержания ванадия (таблица). Во всех кристаллах разной интенсивности голубой окраски содержания $\mathrm{V}$ минимальны и находятся на пороге чувствительности анализа ICP MS, достигая $0.0005 \%$. Возрастание содержаний его соответствует усилению доли зеленого цвета в ряду голубовато-зеленый - светло-зеленый - зеленый (от 0.0008 до 0.0016). В группе гелиодора содержание V уменьшается по мере уменьшения доли зеленого цвета и возрастания желтого. Одновременно, как видно из этой таблицы и было показано нами ранее (Юргенсон, Борзенко, 2018), трехвалентное железо и ванадий, замещающие Al в октаэдрических позициях, ведут себя как антагонисты в зеленом берилле и гелиодоре.

\section{Выводы}

1. Все кристаллы берилла Шерловой Горы, независимо от окраски, относятся к слабощелочным.

2. Максимальные содержания общего железа типично для ярко-голубого аквамарина и оливковозеленого гелиодора.

3. Различия в окраске ювелирных аквамарина, зеленого берилла и гелиодора определяется соотношением окисного и закисного железа.

4. Типохимическим признаком зеленого берилла Шерловой Горы является максимально высокое содержания $\mathrm{V}$ и примерно равные соотношения двух- и трехвалентного $\mathrm{Fe}$.

Работа выполнена в рамках темы НИР №0386-2017-0006.

\section{Литература}

1. Гайворонский Б.А. Шерловогорское месторождение // Месторождения Забайкалья. М.:Геоинфоорммарк. 1995. T. 1. Кн. 1. С. 130-133.

2. Юргенсон Г.А., Борзенко А.А. Ванадий в кристаллах берилла Шерловой Горы (Юго-Восточное Забайкалье) // Успехи современного естествознания. 2018. № 5. С. 164-168.

3. Yurgenson Georgiy, Kononov Oleg. Sherlova Gora: Deposit for Gemstones and Rare Metals: // Sherlova Gora/ Mineralogical Almanac. V. 19. is. 2. 2014. Lakewood, USA: Mineral-AlmanacLtd. P. 12-93. 